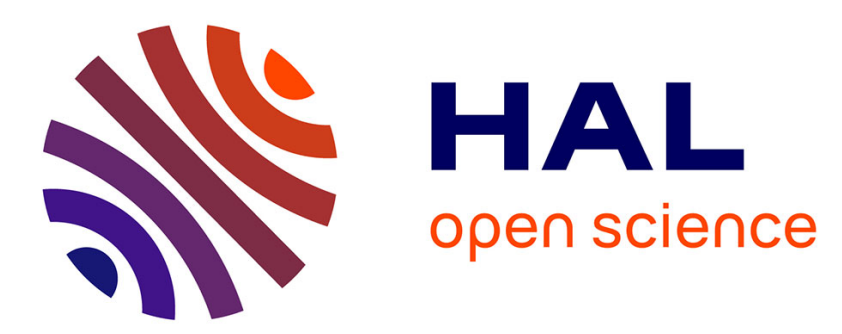

\title{
Numerical and reduced-scale experimental investigation of blast wave shape in underground transportation infrastructure
}

\author{
Olivier Pennetier, Mame William-Louis, André Langlet
}

\section{To cite this version:}

Olivier Pennetier, Mame William-Louis, André Langlet. Numerical and reduced-scale experimental investigation of blast wave shape in underground transportation infrastructure. Process Safety and Environmental Protection, 2015, 94, pp.96-104. 10.1016/j.psep.2015.01.002 . hal-01144129

\author{
HAL Id: hal-01144129 \\ https://hal.science/hal-01144129
}

Submitted on 21 Apr 2015

HAL is a multi-disciplinary open access archive for the deposit and dissemination of scientific research documents, whether they are published or not. The documents may come from teaching and research institutions in France or abroad, or from public or private research centers.
L'archive ouverte pluridisciplinaire HAL, est destinée au dépôt et à la diffusion de documents scientifiques de niveau recherche, publiés ou non, émanant des établissements d'enseignement et de recherche français ou étrangers, des laboratoires publics ou privés. 


\title{
Numerical and reduced-scale experimental investigation of blast wave shape in underground transportation infrastructure ${ }^{(*)}$
}

\author{
Olivier Pennetier ${ }^{\mathrm{a}, *}$, Mame William-Louis ${ }^{\mathrm{a}}$, André Langlet ${ }^{\mathrm{a}}$ \\ ${ }^{a}$ Univ. Orléans, INSA-CVL, PRISME, EA 4229, F45072, Orléans, France.
}

\begin{abstract}
When an explosion occurs in a tunnel, the study of the blast wave quickly becomes complicated, owing to the multiple propagation patterns of the blast wave (Incident wave, regular and Mach reflections) and to the geometrical conditions. Considering this problem, two patterns can be revealed. Near the explosive, the well known freefield pressure wave can be observed. After multiple reflections on the tunnel's walls, this overpressure behaves like a one-dimensional (1D) wave. One aim of this paper is to determine the position of this transition spherical-to-planar wave propagation in a tunnel using both numerical and reduced-scale experiments, and thereby validate the dedicated law established in a previous work.

For this purpose, a detonation of TNT in a tunnel with a cross-section of up to $55 \mathrm{~m}^{2}$ is considered. Results show good agreement between the numerical simulations and experiments. The transition zone between the three-dimensional (3D) and the $1 \mathrm{D}$ wave is well detected. An application to a simplified subway station is also investigated which shows that significant planar waves can be transmitted to the neighboring stations via the junction tunnels.

Keywords: Blast wave, Confined domain, Reduced scale experiment, 3D numerical simulation, risk assessment
\end{abstract}

*corresponding author : 63 Av. de Lattre de Tassigny F18020 Bourges France

Email address: olivier.pennetier@univ-orleans.fr (Olivier Pennetier)

(^) published in Process Safety and Environmental Protection, 2015

Preprint submitted to Elsevier

April 21, 2015 


\section{Introduction}

In urban areas, many tunnels and covered ways can be found, built for road and rail traffic. These geometrical configurations can be considered as tunnels of various lengths and cross sections. As hazardous materials or explosive devices may transit in these areas, the risk of accidents due to the explosion of reactive materials must be considered. Explosions might come from solid detonating materials, gas or flammable gas-air mixtures. The effects of such explosions, resulting from accidents or deliberate acts, are increased by the semi-confined configuration of the tunnels. The front-wave shape is strongly dependent on the geometry and the overpressures can produce severe injuries or lethal issues.

Blast waves have been studied by many authors, in the free-field, and in confined or semi-confined areas. In this case, two patterns can be found: one in a free field, before any perturbing reflection, the other one including multiple reflections. For the first propagation pattern, in the free-field case, different authors have proposed suitable laws, allowing the overpressure peak to be determined on the basis of the radial distance and the quantity of energy released by solid explosive [1, 4]. More recently, [8] have given different expressions of the incident pressure wave depending on the explosive mass and the radial distance. In the case of flammable gas-air mixture detonations, [6] have proposed a polynomial fitting of the blast wave, including the incident angle and allowing the application times and the negative pressure for incident and reflected waves to be determined. The TM5 manual [27] is useful in approaching the blast phenomena and their consequences on structures.

The second propagation pattern concerns confined or semi-confined explosions. The approach is more complex, and was mostly investigated by using numerical tools. Among others, numerical codes, such as AUTODYN [30], LS-DYNA [11], EUROPLEXUS [17], CONWEP [23] or self-developed CFD (computational fluid dynamics) codes as used by [2], require substantial computer resources to provide realistic simulations. In the different tunnel studies, many authors have focused on the mechanical effects of an explosion on the structure of the tunnels whereas a few have presented the behavior of the blast wave in the tunnel. Some of these studies include computations with obstacles and venting devices. For a semi-confined configuration, [22] has discussed the small-scale modeling of explosive blasts in urban scenarios using both experiments and numerical simulations. Working specifically on tunnels, [11] used LS-DYNA to study the mechanical behavior of subway stations made of concrete submitted to an explosion of $50 \mathrm{~kg}$ of TNT (trinitrotoluene). [7] used a finite element method to describe the behavior of a tunnel submitted to the blast generated by the explosion of an LPG (liquefied petroleum gas) tank, coupling the thermal and mechanical aspects. [28] also computed the consequences 
of a pressure vessel exploding in a tunnel system with branched ducts for smoke evacuation. [17] studied venting protection systems in trains with explosions of up to $25 \mathrm{~kg}$ of TNT. [26] have computed the damage of an explosion of $250 \mathrm{~kg}$ of TNT in a railway station using a CFD method. [21] have also used a CFD method to simulate the pressure wave propagation in a small-scale branched tunnel. Computations may lead to good approaches and give a better knowledge of the phenomena with realistic representations.

Experimental works on tunnel explosions are hardly ever found in literature, as has already been outlined by some authors [18]. The results of some full scale experiments can be found in the works of [10], who studied explosions in Swedish military tunnels, and in a report of the US army [14]. The METRO project [13] is a recent and large collaborative project about tunnels, and in addition to smoke, fire and other problems, one part of this work is devoted to damage to underground transportation, including explosions occurring inside the trains. Using plastic explosive $\mathrm{PE} 4$, very close to the plastic explosive $\mathrm{C} 4$, the influence of rigid obstacles in small scale tunnels has been experimentally studied by [25]. To summarize the state of the art on this subject, experimental data on time-dependent pressures, arrival times in tunnels or subway stations and air-blast shape in tunnels due to an explosive device do not seem to be published often in the literature.

In a confined domain, before any reflection on obstacles, a blast wave propagates as in a free-field. In this phase, the blast wave is spherical and the maximum peak of overpressure can be described with a free-field decay law [12]. After reflection on the walls, the wave exhibits a different shape which can be predicted by a driven decay law dedicated to planar waves [24]. So, by knowing the transition zone between those two different propagation patterns, one can determine the incident overpressure at any location in the tunnel. This was investigated by [3], who proposed a suitable law to locate the transition zone issued from numerical simulations of the detonation of TNT in a tunnel. [3] also showed that planar waves can spread over long distances with small damping effects on the incident overpressures. So, the spatial evolution of the incident overpressure shows a less steep slope than in the spherical case.

In this paper, the proposed study is to determine this transition zone, by using both numerical simulations and reduced-scale experiments of the detonation of a flammable gas-air mixture in a tunnel. Finally, application to underground stations (metro) is proposed, where the objective consists in predicting whether a significant blast wave can be transmitted or not to a neighboring station via a junction tunnel. 


\section{Description of the numerical solver and the experimental method}

\subsection{The numerical solver}

Blast wave propagation in air is governed by the unsteady Euler equations, which, in the present study, are solved by a home-made solver developed at the University of Valenciennes [29, 2]. The numerical method on which this software's solver is based, is an unstructured finite-volume cell-centered approach using the traditional upwind scheme and a two-stage explicit time integration technique, which gives an accuracy of the second-order in both space and time. In order to prevent numerical oscillations, which may occur in regions with strong gradients, the minmod limiter was used. The spatial discretization was performed with an automatic Cartesian grid generator [9].

\subsection{The experimental methodology}

\subsubsection{Scale models and Similarity law}

In detonics, working on real scale structures is very expensive and the quantities of explosive used can be substantial. So, these full scale experiments often involve working in a restricted and secured area, due to the high levels of pressure produced, flying shrapnel and the use of sensitive explosive devices. An alternative experimental method consists in using reduced scale models, which allow experimental works to be safely performed in research laboratories. A previous work [19] presented the evaluation of the vulnerability of a vehicle facing the action of a landmine. This work was realized using a $1 / 10^{\text {th }}$ scale model on which pressure and impulse fields were determined. Considering the Hopkinson similarity law, it is well established that for homothetic detonations, the whole history of the pressure field is identical for both the actual and reduced scale and the application times are multiplied by the scale ratio of the experiment [15]. The lengths must be within the scale factor. Consequently, the masses of the explosive, being the product of density and volume, have to be within the cubic root of the scale factor. This law has been verified, using propane-oxygen mixtures, with tests over a large range of flammable mixture volumes $\left(1.6-510 \mathrm{~m}^{3}\right)[5]$.

\subsubsection{The explosive}

As a general rule, solid explosives are employed in studies of detonics (e.g. PETN (pentaerythritol tetranitrate), C4, ANFO (ammonium nitrate-fuel oil), TNT...). In the laboratory, particularly for safety reasons, flammable gaseous mixtures are used instead of solid explosives. Considering energetic equivalences, one can generate the equivalent explosive power of a few milligrams of TNT by a given volume of a 
flammable gaseous mixture. The reactive medium used in this work was a stoichiometric mixture of propane and oxygen $\left(\mathrm{C}_{3} \mathrm{H}_{8}+5 \mathrm{O}_{2}\right)$. The gaseous mixture has to be confined in a spherical or hemispherical volume to keep its initial molar concentration constant and to control the energy released in the explosion process. This confinement must also be as immaterial as possible to keep the flammable gaseous medium pressure equal to the atmospheric pressure. In the present experiments, the mixture was injected through an aqueous solution of sodium oleate, which is a soap emulsifier, enabling the formation of hemispherical bubbles. During the experiment, a bubble with the flammable mixture is made in a few seconds and the explosion is started a maximum of $5 \mathrm{~s}$ after producing the bubble. So, no diffusion phenomena can affect the composition of the bubble. The volumetric energy of this mixture is $14.16 \mathrm{MJ} / \mathrm{m}^{3}$ at $20^{\circ} \mathrm{C}$. According to the works of [1], the specific energy of TNT is $4.69 \mathrm{MJ} / \mathrm{kg}$ and the equivalency ratio, in terms of energy, between a propane-oxygen gaseous mixture and TNT is equal to 5 ([5], [16]). Considering the initial number of moles of the mixture, to obtain the same mechanical effects on a structure at a same radial distance, at $20^{\circ} \mathrm{C}, 1.65 \mathrm{~m}^{3}$ of this gaseous mixture is equivalent to $1 \mathrm{~kg}$ of TNT.

\subsubsection{Creating a detonation}

Depending on the quantity of energy igniting the explosion, either a deflagration or a detonation can be obtained. To obtain a detonation, which is deterministic, an energy of at least $20 \mathrm{~J}$ is necessary to initiate this specific mode of explosion, using an exploding wire. A thin copper wire is welded between two electrodes. Then, high voltage coming from the discharge of high voltage capacitors $(7.5 \mathrm{kV}, 8 \mu \mathrm{F})$, makes the copper wire melt instantaneously thereby creating a plasma. Details on this technique can be found in [20]. This technique is perfectly reproducible and, keeping the same size of the bubbles, one can obtain exactly the same pressure field. This is illustrated in Figure 1, where the effects of three identical detonation experiments on a given pressure sensor are presented, showing a very high level of reproducibility. These signals were obtained from a detonation in a small scale tunnel (square section) with a centered detonation. The pressure is measured at $25 \mathrm{~cm}$ from the center of the explosion. The first peak corresponds to the first incoming incident wave whereas the others correspond to the different reflections such as the side walls, the upper wall and the close-end wall in this example. More details are given in Section 3.3. 


\section{Application I: Blast wave shape in a tunnel}

\subsection{Numerical setup}

For this first setup, a tunnel with a constant square cross section of $5 \mathrm{~m} \mathrm{x} 5 \mathrm{~m}$ is considered at full scale. The length $L$ of the tunnel is equal to $30 \mathrm{~m}$. Considering the symmetry (tunnel and explosion), the propagation domain is discretized into 6.7 million Cartesian cells. Fourteen points of measurement $\left(\mathrm{C}_{1}\right.$ to $\left.\mathrm{C}_{14}\right)$, using a step size of 1.5 meters are placed along the axis of the tunnel (Figure 2). The left side (near the explosive) is closed while the right side is open to the atmosphere, where an outflow boundary condition is applied. The ambient temperature and pressure are set respectively to $20^{\circ} \mathrm{C}$ and $101325 \mathrm{~Pa}$. For the detonation products, the JWL (Jones-Wilkins-Lee) equation of state is used. The simulated configurations involve different weights of TNT ranging from 0.53 to $11.69 \mathrm{~kg}$. The explosive charge is located on the symmetry axis of the tunnel and on the ground level. Table 1 presents the four explosive charges for both full and reduced scale configurations; each explosive mass in the tunnel is characterized by a confinement level $\alpha$, that reads:

$$
\alpha=100 \frac{d_{\text {explosive }}}{d_{h \text { tunnel }}}
$$

where $d_{\text {explosive }}$ corresponds to the diameter of a TNT sphere of this mass and $d_{h}$ is the hydraulic diameter of the tunnel's section, in this case equal to $5 \mathrm{~m}$.

\subsection{Experimental setup}

The experimental setup is a reduced scale model at $1 / 30^{\text {th }}$. The equivalent mass of TNT and corresponding bubble radius are summed up in Table 1 for the experiment. The scaled model is made of laminated wood panels of $27 \mathrm{~mm}$ thickness, locally reinforced with steel profiles. The tunnel is strong enough to withstand the blast wave. A polycarbonate window, closing the tunnel, is fixed at the explosion side, which allows to verify that the bubble did not burst before the initiation. To detect the transition zone (from spherical to planar wave), pressure sensors were placed every $5 \mathrm{~cm}$ along the longitudinal axis of the tunnel, beginning $20 \mathrm{~cm}$ away from the center of the bubble and placed on the same horizontal plane as the charge. Piezo-

electric pressure sensors from Kistler, type 603B (ranging from $10 \mathrm{kPa}$ to $20 \mathrm{MPa}$ ) were used and connected to numeric scopes with charge amplifiers from Kistler, type 5007. A general view of this experimental setup is presented in Figure 3.

\subsection{Results}

Figure 4 presents the iso-Mach distributions (side view) at three different times given by the numerical simulations for the full scale tunnel, using $0.53 \mathrm{~kg}$ of TNT. 
Ten milliseconds after the initiation (Figure 4a), one can see the wave propagation and its interaction with the upper wall. After $20 \mathrm{~ms}$, the incident wave continues to propagate spherically along the tunnel, whereas the reflected one goes towards the bottom plate (Figure 4b). A Mach reflection appears and grows with the displacement of the triple point towards the bottom plate. When the reflected wave reaches the bottom plate, the Mach stem covers the tunnel cross section, and hence, this wave can be considered a planar one, as can be seen at $t=30 \mathrm{~ms}$ in Figure 4c.

Figure 5 presents, for a given explosion (radius of the bubble: $25 \mathrm{~mm}$ ), the evolution of the experimental incident pressures versus time, for all 14 positions along the axis of the tunnel $\left(\mathrm{C}_{1}\right.$ to $\mathrm{C}_{14}$, top to bottom). One can notice the initial pressure peak arising in each signal, which will be used to locate the transition zone. Just after this peak, multiple reflections appear which considerably increase the initial maximum overpressure. This is due to this semi-confined configuration. The arrival time is not a linear function of time as the celerity of the blast wave decreases with the distance.

Figure 6 presents an example of the pressure evolution of sensor $\mathrm{C}_{3}$, located $30 \mathrm{~cm}$ away from the center of the bubble. The hemispherical bubble containing the flammable mixture has a radius of $25 \mathrm{~mm}$. The numerical and experimental pressure curves are similar. Particularly, the arrival time of the first peak of pressure (incident wave) corresponds exactly to the measured one, even though the numerical simulation was performed using a TNT explosive whereas the experiment was performed with a flammable gaseous mixture. The first peak, point (a), corresponds to the initial incident blast wave. As soon as the wave reaches the walls of the structure, a regular reflection propagates simultaneously from the side walls, the upper wall and the rear face, due to symmetry in the structure and in the position of the explosive. The reflected wave from the rear face propagates longitudinally towards the pressure sensor and is superimposed on the value of the first decreasing overpressure, which can be seen at point (b). The highest overpressure signal, point (c), corresponds to the conjunction of three reflection waves, coming respectively from the two lateral walls and the upper one. Numerically, considering the symmetry of the problem, these three shock waves converge at the same time at pressure sensor $\mathrm{C}_{3}$. However, in the experiment, slight defects of symmetry do exist, due to the centering of the calibration ring, the position of the exploding wire, and the manufacturing tolerance of the structure. Figure 6 shows that point (c) corresponds to the superposition of the regular reflections mentioned above, leading to the maximum pressure peak. These three reflections, slightly differing in arrival time, are distinguishable in the experimental data and denoted (I), (II) and (III) in Figure 6, but cannot be seen in the simulation as symmetry conditions are perfect. The simulated arrival times on 
all the other sensors also match well with the experimental ones.

The numerical rise time of the detonation peak pressure (about $15 \mu \mathrm{s}$ ), is not as fast as during the experiment (typically less than $5 \mu \mathrm{s}$ ) and also the amplitude of the peak of pressure is underestimated by the numerical simulation. This is due to the numerical dissipation which is linked to the mesh size. To reduce this damping effect, smaller grid cells are needed, which will require more computer resources.

Let us consider $Z$, called the reduced distance, as the ratio of the distance explosive - pressure sensor (denoted $d_{i}$ ) by the cube root of the mass of the explosive. When plotting the first maximum incident overpressure (e.g. point (a) mentioned in Figure 6) versus $Z$, the spatial evolution shows a first spherical propagation followed by an abrupt increase in the pressure, as can be seen in Figure 7 . This is particularly obvious for radius R25, R36 and R50 and can be easily deduced for the stronger detonation (R70) in this figure. Thereafter, a second propagation pattern appears and characterizes the driven decay law for a planar wave. A transition zone between the two decay laws can be shown. In the present study, this transition zone is characterized by the location of its beginning from the ignition point and denoted $Z_{t r}$. This location depends on the quantity of explosive and on the geometry. It can be deduced from the following equation (Benselama et al., 2010):

$$
Z_{t r}=\frac{0.0509}{(\alpha / 100)^{13 / 9}}
$$

The evolution of $Z_{t r}$ versus the confinement level $\alpha$ for the tunnel is presented in Figure 8 where the numerical simulation, the $Z_{t r}$ equation and the experiments are compared. A good agreement is obtained between the three methods.

\section{Application II: Blast wave shape in a subway station}

Considered vulnerable places, subway stations and the underground can be characterized as a space with a high concentration of people in a reduced area, particularly during rush hours. They are considered potential targets for terrorists using Improvised Explosive Devices (IEDs). The last 20 years has seen events in subways or in railway stations from among which can be mentioned the attacks in Paris (1995, 1996), Tokyo (1995), Madrid (2004), London (2005), Moscow (2004, 2010) and more recently in Minsk in 2011 [13], involving multiple fatalities and scores of injured people.

Here an explosion in a simplified subway station with a tunnel junction is considered (Figure 9). In this first attempt, the trains are not included in the model. The blast wave propagation and its shape are studied, using experiment and numerical 
simulation, both at $1 / 100^{\text {th }}$ reduced scale (Figure 10). The explosion is tested using a hemispherical bubble (diameter $=5 \mathrm{~cm}$ ), which corresponds to $19.80 \mathrm{~kg}$ of TNT at full scale. This detonation is initiated in the middle part of the station, along the platform (point A), as indicated in Figures 9 and 11. The incident pressures are measured at six different positions (Figure 11). Two are located in the station $\left(\mathrm{C}_{2}\right.$ and $\left.\mathrm{C}_{5}\right)$, one is at the station - tunnel interface $\left(\mathrm{C}_{8}\right)$ and the three remaining points are positioned along the axis of the tunnel $\left(\mathrm{C}_{9}, \mathrm{C}_{10}\right.$ and $\left.\mathrm{C}_{14}\right)$, at 10, 20 and 60 $\mathrm{cm}$ respectively from the entrance of the tunnel. For the numerical simulation, only half of the model is discretized with $2.3 \times 10^{6}$ Cartesian cells due to the symmetry. In this case, no TNT equivalency is used for the simulation as the reduced scale configuration is directly simulated considering the gaseous bubble. Some additional measurement points are added in the numerical simulation, whose position ranges from $3 \mathrm{~cm}$ from the ignition position to $20 \mathrm{~cm}$ (gauge $\mathrm{C}_{2}$ ). In order to obtain a first insight of the transition zone, the correlated law (equation 2) can be used. As the explosive is not centered in the station, some correction parameters have to be applied to the equation 2 as discussed in a previous work [3]. In this case, the correction parameters are a multiplying factor $\beta$ of 1.8 applied to the explosive mass, the use of $d^{\prime}=\sqrt[3]{\beta} d$ instead of $d$ and a correction of the hydraulic diameter $d_{h}$ which is replaced by $4 / 3 d_{h}$. This leads in this case to a global correction factor to equation 2 equal to 1.14 .

The transition zone $Z_{t r}$ obtained corresponds to a distance $d_{i}$ equal to $13.49 \mathrm{~m}$ from the center of the explosion $\left(13.49 \mathrm{~cm}\right.$ at scale $\left.1 / 100^{t h}\right)$, close to the ignition point. The numerical simulation was realized with outputs both in the station and in the tunnel. As a result, plotting the initial peak of incident pressure, denoted $\Delta P^{+}$, versus $Z$ for the different sensors, the transition zone appears for a value of $Z$ equal to 5.14, which corresponds to a distance of $13.9 \mathrm{~cm}$ from the center of the explosion (Figure 12), which fits well with the value calculated with equation 2 . The two different zones of the problem clearly appear in this figure (station and tunnel) and the main jump corresponds to the transition planar-to-spherical. One can notice a first jump before the main one. This corresponds to the arrival of a planar wave in the vertical plane, which is the shortest distance compared to the horizontal one (4.4 m compared to $12.5 \mathrm{~m}$ ). This wave is still spherical in the horizontal plane and then becomes fully planar in the second transition zone. One can notice that the slope of the curve is less steep after the transition zone. This also characterizes the $3 \mathrm{D}$ and the $1 \mathrm{D}$ propagation pattern. The overpressure, initially peaking at $720 \mathrm{mbar}$ at probe 8 (entrance of the tunnel), still reaches 429 mbar (60\% of the initial overpressure) at the exit point (Figure 12). So, this blast wave can still generate heavy damage in the neighboring subway station, provided that the tunnel between these two stations 
is not very long.

The first reflections of the pressure wave act on the ceiling of the subway station and the Mach stem grows very quickly. The planar wave propagates through the station and when it travels into the tunnel, the $1 \mathrm{D}$ configuration is preserved. This evolution can be visualized with iso Mach curves at different times, as presented in Figure 13.

To get a better view of the shock waves inside the tunnel, a 3D plot is presented in Figure 14 at two given times (cases (a) and (b), respectively $0.104 \mathrm{~ms}$ and $0.204 \mathrm{~ms}$ ). Figure 14 -case (a)- shows a snapshot of the incident shock wave and the Mach stem before the transition zone. Figure 14 -case (b)- presents a snapshot when the shock wave has just become planar, i.e. when the Mach stems coming from each side of the tunnel meet. One can notice that the iso-curves are not symmetric with regard to the central axis, which makes sense as the location of the explosive is not on the axis of the tunnel but on the off-axis platform.

Figures 15 and 16 present the comparison of the pressure history both experimentally and by simulation at six different positions. In the tunnel the front wave is planar, as discussed before. The signal is composed of multiple reflections, leading to the arrival of secondary shocks towards a first quasi triangular signal of pressure as the wave spreads through the tunnel, as seen in Figure 16(c). Numerical calculations and experiments give similar results, considering the different arrival times, the overpressures and the shape of the decreasing pressure. Considering the waves in the station (e.g. Fig. 15(a)), one can notice more complex phenomena, with high pressures peaks, about twice the maximum value in the tunnel, followed by secondary shocks and multiple reflections (coming from the side walls and ceiling). Simulations and experiments are very similar to one another despite the complexity of the problem.

The experiments and simulations, based on a simplified existing subway station and tunnel junction, show that if a detonation occurs in the middle of a station on the platform, the blast wave quickly becomes planar and then propagates through the opposing tunnels at a slowly decreasing celerity and pressure. Figure 17 presents the evolution of the blast wave celerity versus $Z$. At the tunnel exit, the celerity is close to $400 \mathrm{~m} / \mathrm{s}$ for the studied length, and would evolve towards the velocity of sound for a very long tunnel.

\section{Conclusions}

In this paper, the experimental and numerical simulation of blast waves in two different tunnels is presented. Using the Hopkinson similarity law, the results obtained on scale models can be easily transposed to full scale structures. 
In a first case, a simple tunnel is considered. The experiments are carried out at a $1 / 30^{\text {th }}$ reduced scale using a gaseous flammable mixture. The corresponding full scale tunnel is simulated numerically using a self-developed CFD code. The comparison between the experimental and numerical results shows a very good level of agreement. The transition zone spherical-to-planar wave pattern is determined both experimentally and numerically and is in agreement with the computed results obtained from an equation derived in previous works.

In a second case, the explosion of the equivalent of $19.80 \mathrm{~kg}$ of TNT in a subway station modeled at $1 / 100^{\text {th }}$ scale is considered. The numerical pressure history at different locations in the station and in the tunnel also gives good results compared to the experimental ones. It shows that the blast wave becomes planar in the station and that a significant shock wave is transmitted in the tunnel and may propagate towards the neighboring subway station where it can cause damage.

\section{References}

[1] Baker, W., Cox, P., Westine, P., Kulesz, J., \& Strehlow, R. (1983). Explosion hazards and evaluation. Fundamentals studies in engineering. Elsevier, New York.

[2] Benselama, A. M., William-Louis, M. J.-P., \& Monnoyer, F. (2009). A 1D-3D mixed method for the numerical simulation of blast waves in confined geometries. Journal of Computational Physics, 228, 6796 - 6810.

[3] Benselama, A. M., William-Louis, M. J.-P., Monnoyer, F., \& Proust, C. (2010). A numerical study of the evolution of the blast wave shape in tunnels. Journal of Hazardous Materials, 181, 609 - 616.

[4] Brode, H. (1955). Numerical solution of spherical blast waves. Journal of Applied Physics, 26, $766-775$.

[5] Brossard, J. (1982). Les essais AMEDE 2/8 et premiers résultats de synthèse. EA 79.15. Technical Report ENSMA, Poitiers, France.

[6] Brossard, J., Desrosier, C., Renard, J., \& Purnomo, H. (1995). Pressure loads on a plane surface submitted to an explosion. 19th Int. Symp. on Shock Waves, 4, 387-392.

[7] Buonsanti, M., \& Leonardi, G. (2013). 3D simulation of tunnel structures under blast loading. Archives of Civil and Mechanical Engineering, 13, 128 - 134. 
[8] Chang, D., \& Young, C. (2010). Probabilistic estimates of vulnerability to explosive overpressures and impulses. Journal of Physical Security, 4, $10-29$.

[9] Deister, F., Waymel, E., Hirschel, F., \& Monnoyer, F. (2002). Self-organizing hybrid cartesian grid generation and application to external and internal flows. In Numerical flow simulation III, notes on Numerical Fluid Mechanics and Multidisciplinary Design (pp. 18 - 29). volume 82.

[10] Forsén, R., Berglund, R., Carlberg, A., \& Dalenius, R. (2012). The Swedish tunnel trials - a comparison between test and calculations. In Proceedings of $M A B S$ 22. Bourges, France.

[11] He, W., Chen, J.-Y., \& Guo, J. (2011). Dynamic analysis of subway station subjected to internal blast loading. Journal of Central South University, 18, $917-924$.

[12] Henrych, J. (1979). The dynamics of explosion and its use. Elsevier, Amsterdam.

[13] Ingason, H., \& Nilsson, D. (2012). The METRO project, final report. Technical Report Mälardalen University Press.

[14] Joachim-Charles, E. (1990). Shallow underground tunnel / chamber, explosion test program, summary report - structures laboratory SL-90-10. Technical Report Department of the Army, US Army Corps of Engineers.

[15] Kinney, \& Gilbert, F. (1962). Explosive shocks in air. New York: The Mc Millan Co.

[16] Lannoy, A. (1984). Analyse des explosions air-hydrocarbure en milieu libre : Etudes déterministe et probabiliste du scénario d'accident. Prévision des effets de suppression. Bulletin Direct. Etudes et Recherches EDF. A4. Technical Report EDF, France.

[17] Larcher, M., Casedei, F., \& Solomos, G. (2010). Influence of venting areas on the air blast pressure inside tubular structures like railway carriages. Journal of Hazardous Materials, 183, 839 - 846.

[18] Liu, J., Yan, Q., \& Wu, J. (2008). Analysis of blast wave propagation inside tunnel. In Transactions of Tianjin University (pp. 358 - 362). volume 14.

[19] Pennetier, O., Desrosier, C., Renard, J., \& Deprince, X. (2004). Experimental study of vehicles submitted to the blast wave of a mine: pressure and impulse measurements. In Proceedings of $M A B S$ 18. Bad Reichenhall, Germany. 
[20] Ram, O., \& Sadot, O. (2012). Study of blast wave, structure interaction using exploding wire technique. In Proceedings of $M A B S$ 22. Bourges, France.

[21] Rigas, F., \& Sklavounos, S. (2005). Experimentally validated 3-D simulation of shock waves generated by dense explosives in confined complex geometries. Journal of Hazardous Materials, 121, 23 - 30.

[22] Ripley, R. (2004). Small-scale modeling of explosive blasts in urban scenarios. In Proceedings of the 21st International Symposium on ballistics. Adelaide, Australia.

[23] Rouquand, A. (2012). A simplified approach using the conwep software that simulates the effect of shock wave reflections. In Proceedings of MABS 22. Bourges, France.

[24] Silvestrini, M., Genova, B., \& Leon Trujillo, F. (2009). Energy concentration factor. A simple concept for the prediction of blast propagation in partially confined geometries. Journal of Loss Prevention in the Process Industries, 22, $449-454$.

[25] Smith, P., Vismeg, P., Teo, L., \& Tingey, L. (1998). Wave transmission along rough-walled tunnels. International Journal of Impact Engineering, 21, 419 432.

[26] Solomos, G., Casedei, F., \& Giannopoulos, G. (2010). Assessment of explosion effects in railway stations. In Proceedings of Urban Habitat Constructions under Catastrophic Events (pp. 629 - 634).

[27] TM5-1300 (1990). The design of structures to resist the effect of accidental explosions, technical manual. Technical Report US department of the army, Navy and Air force, Washington DC.

[28] Van den Berg, A., \& Weerheijm, J. (2006). Blast phenomena in urban tunnel systems. Journal of Loss Prevention in the Process Industries, 19, 598 - 603.

[29] Waymel, F., Monnoyer, F., \& William-Louis, M. J.-P. (2006). Numerical simulation of the unsteady three-dimensional flow in confined domains crossed by moving bodies. Computers and Fluids, 35, 525 - 543.

[30] Zyskowski, A., Sochet, I., Mavrot, G., Bailly, P., \& Renard, J. (2004). Study of the explosion process in a small scale experiment - structural loading. Journal of Loss Prevention in the Process Industries, 17, 291 - 299. 


\begin{tabular}{|c|c|c|c|c|c|}
\hline \multicolumn{2}{|c|}{ Configuration } & $\mathrm{N}^{\circ} 1$ & $\mathrm{~N}^{\circ} 2$ & $\mathrm{~N}^{\circ} 3$ & $\mathrm{~N}^{\circ} 4$ \\
\hline Full scale & $\begin{array}{l}\text { Equivalent mass of } \\
\text { TNT (kg) }\end{array}$ & 0.53 & 1.59 & 4.27 & 11.69 \\
\hline -Numerical- & $\begin{array}{l}\text { Spherical diameter of } \\
\text { TNT }-d_{\text {explosive }}(\mathrm{mm})-\end{array}$ & 85 & 122 & 170 & 238 \\
\hline $\begin{array}{lr}\text { Reduced } & \text { scale } \\
\left(1 / 30^{t h}\right) & \text { (Experi- } \\
\text { mental) } & \end{array}$ & $\begin{array}{ll}\text { Equivalent } & \text { bubble } \\
\text { radius } R(\mathrm{~mm}) & \end{array}$ & 25 & 36 & 50 & 70 \\
\hline \multicolumn{2}{|c|}{ Ratio $\alpha(\%)$} & 1.70 & 2.45 & 3.41 & 4.77 \\
\hline
\end{tabular}

Table 1: Different explosive configurations for experiments and numerical simulations -Application I- 


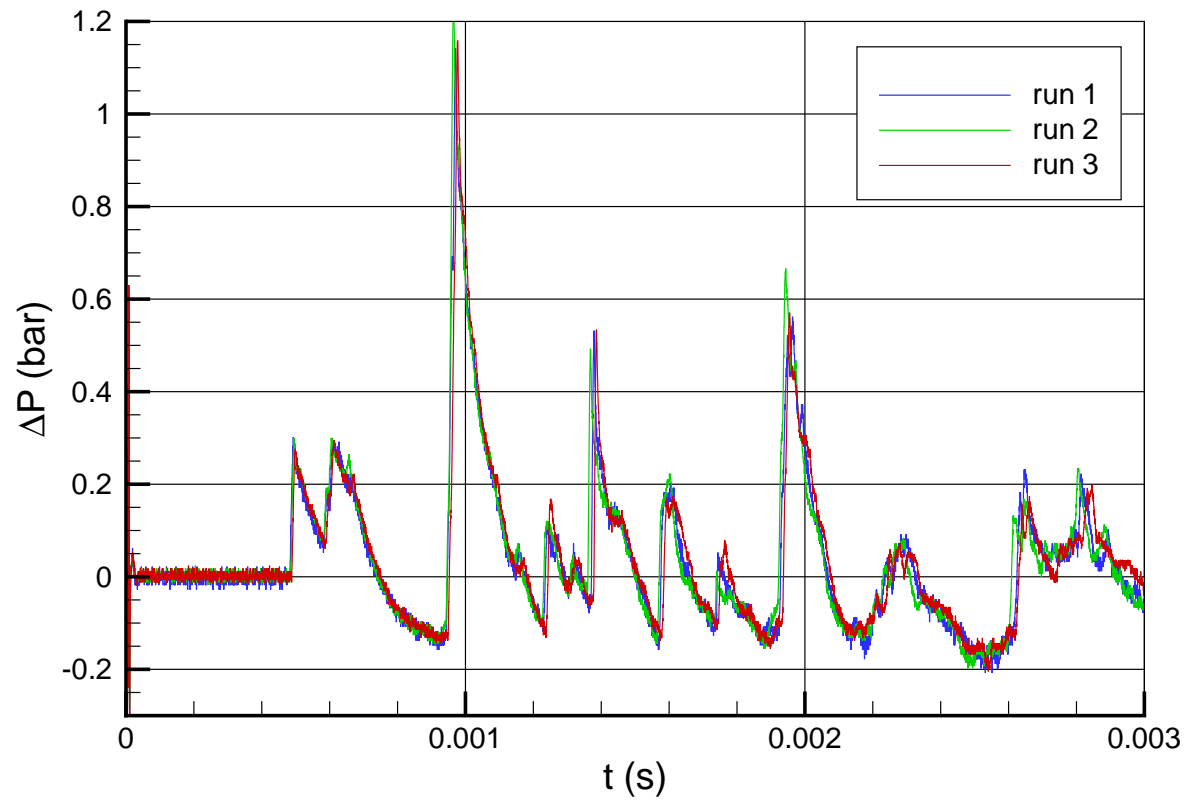

Figure 1: Reproducibility of the tests for a given detonation (pressure sensor position : $25 \mathrm{~cm}$ from the center of the explosion, bubble radius : $25 \mathrm{~mm}$ ) 


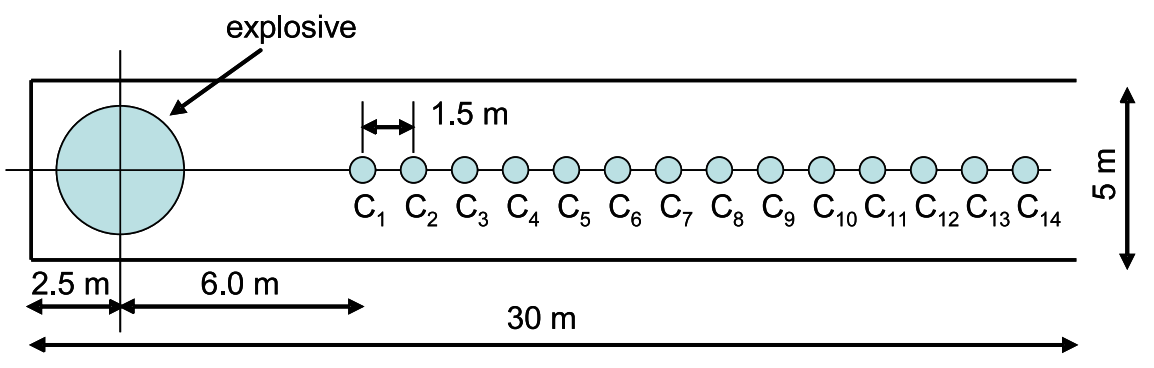

Figure 2: Configuration of the study - top view -Application I- 


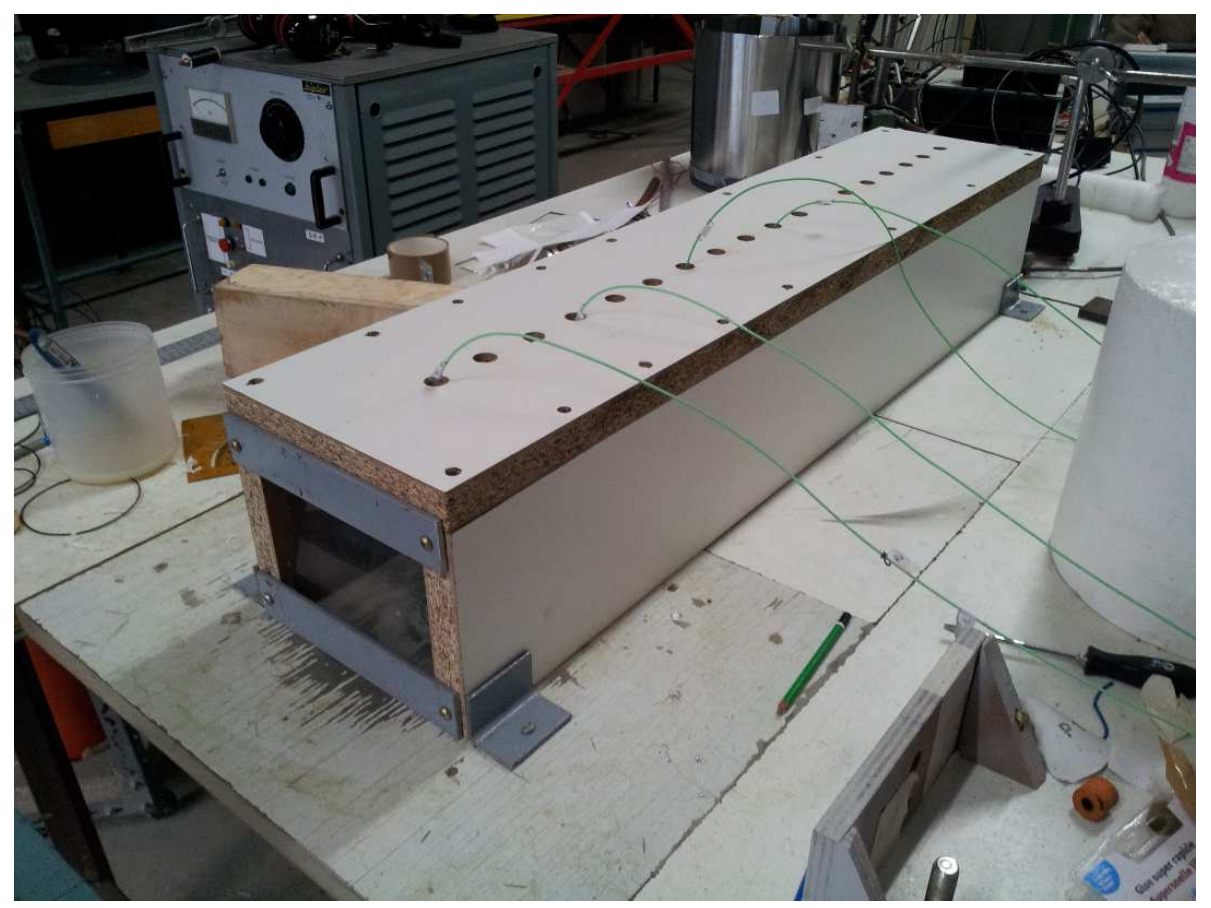

Figure 3: Experimental configuration -Application I- 

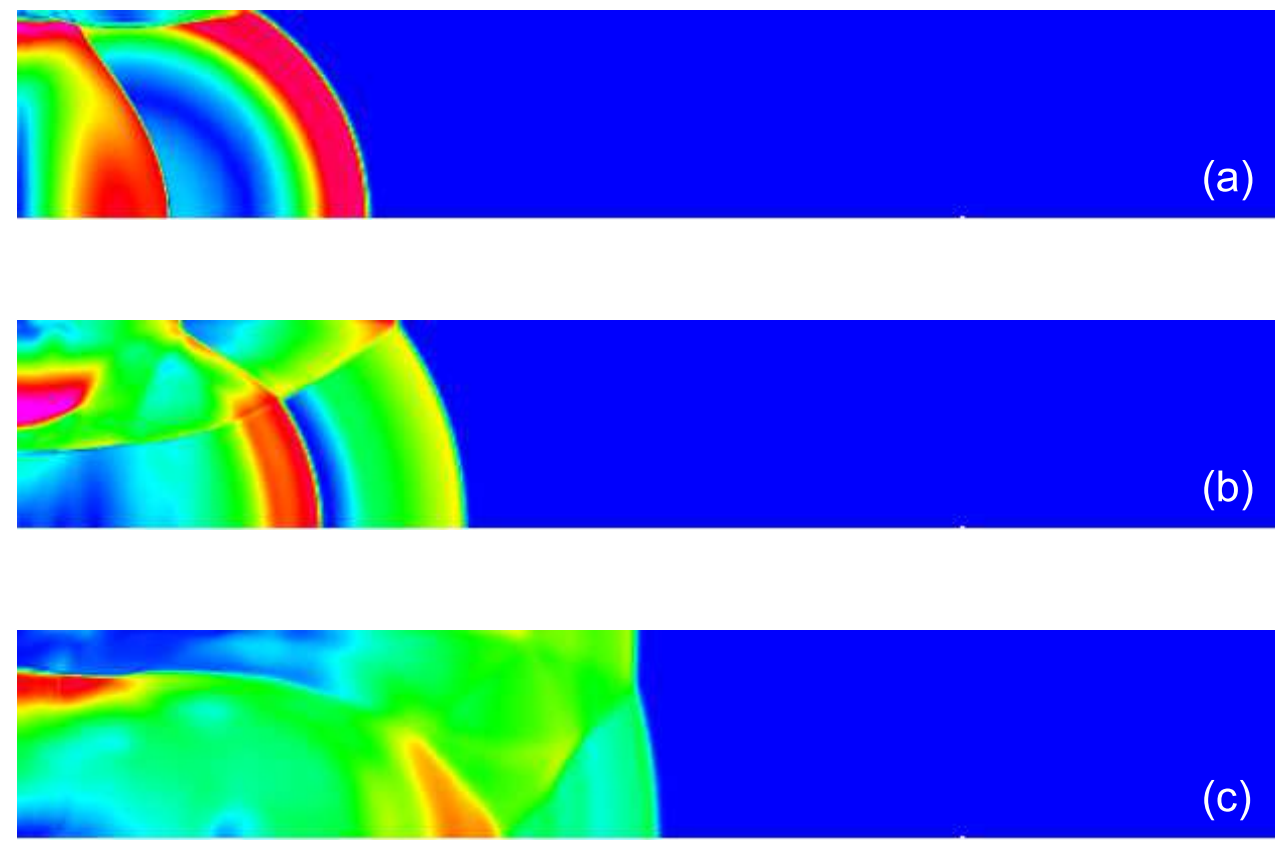

Figure 4: iso Mach at different times $(t=10 \mathrm{~ms}, 20 \mathrm{~ms}$ and $30 \mathrm{~ms}$, from top to bottom), side viewbubble $\mathrm{R}=25 \mathrm{~mm}-$ Application I- 


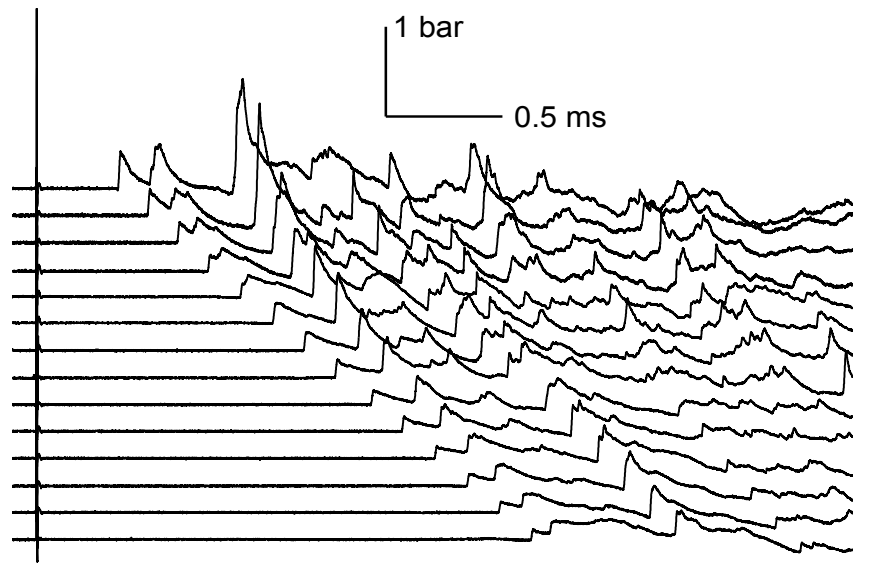

Figure 5: Experimental pressure history in the tunnel $\left(\mathrm{C}_{1}\right.$ to $\mathrm{C}_{14}$ - from top to bottom) Bubble $\mathrm{R}=25 \mathrm{~mm}$, -Application I- 


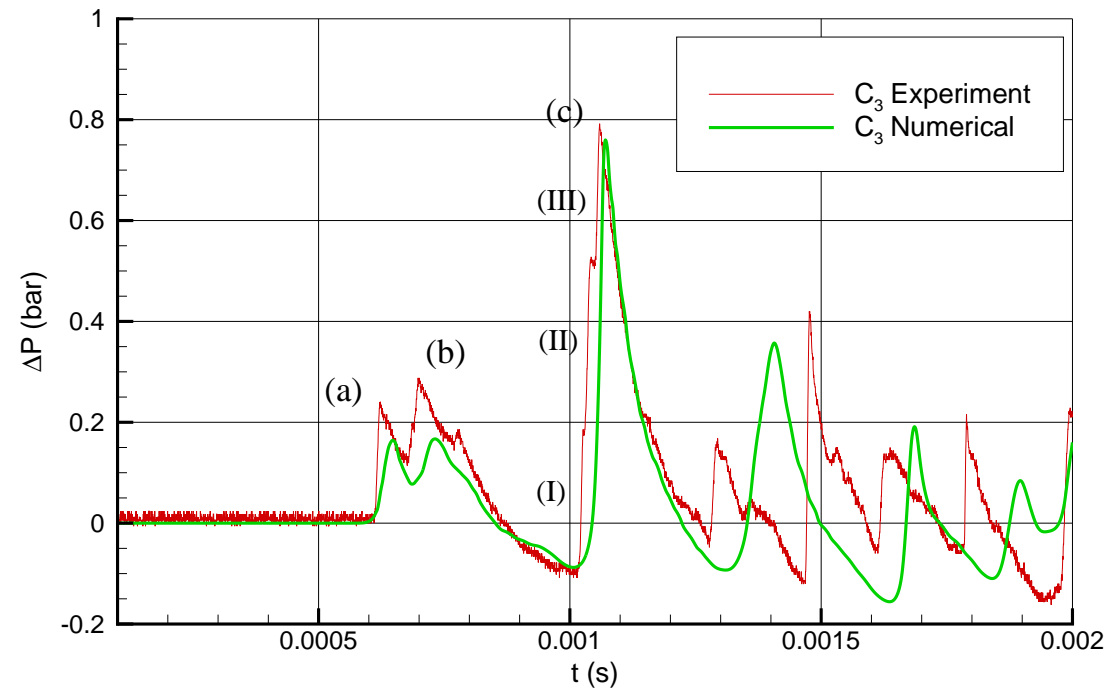

Figure 6: Experimental and numerical pressure versus time at $30 \mathrm{~cm}$ from the center of the detonation (sensor $\mathrm{C}_{3}$, bubble $\mathrm{R}=25 \mathrm{~mm}$ ) -Application I- 


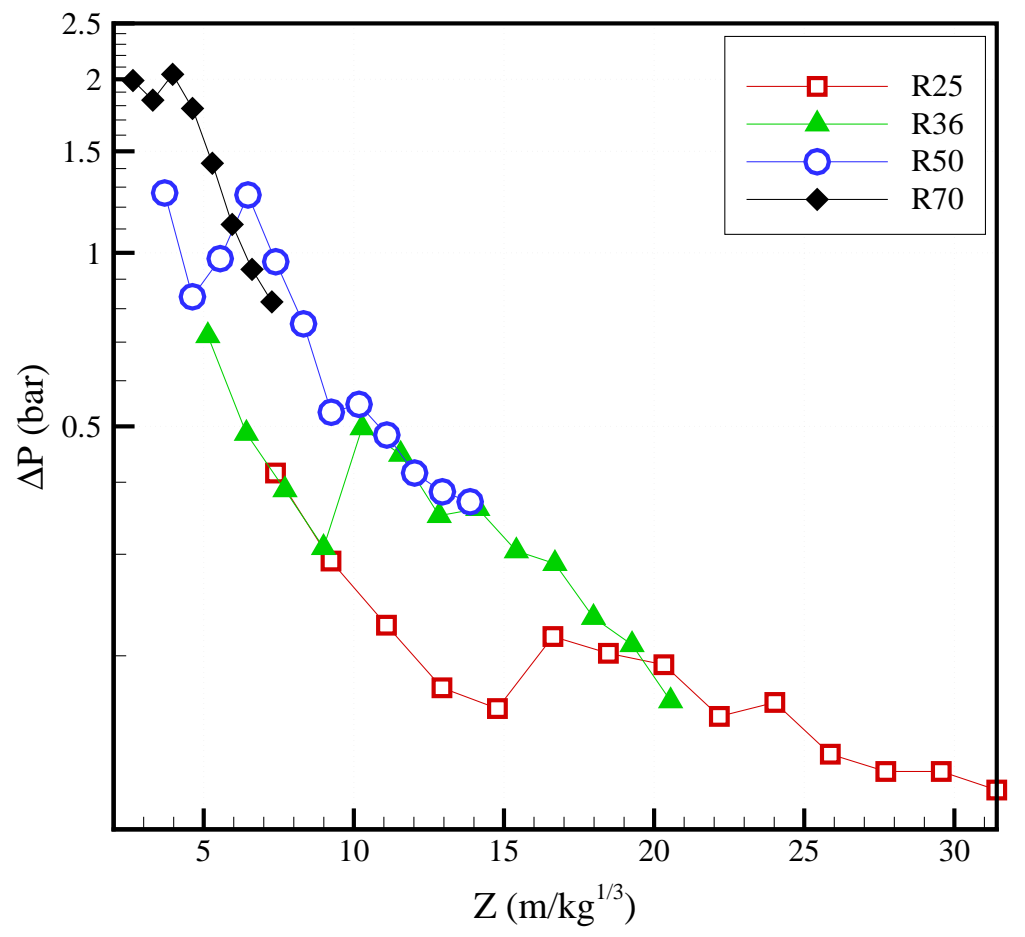

Figure 7: Incident pressure along the tunnel -Application I- 


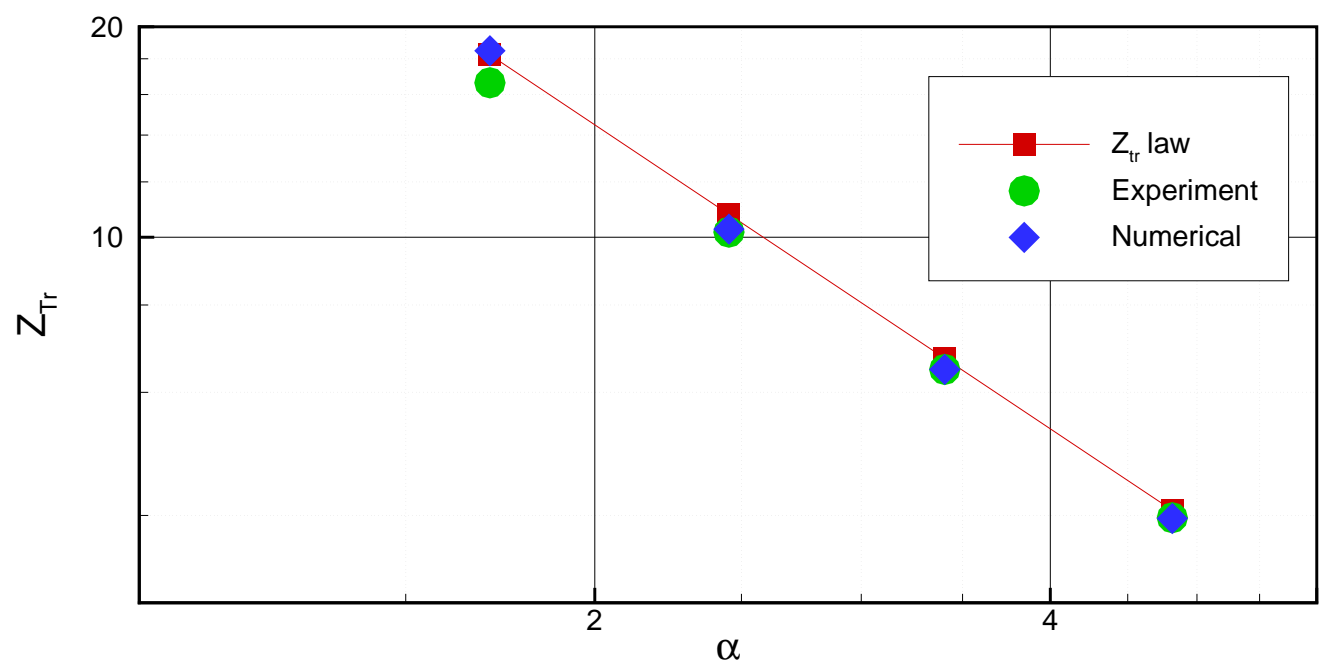

Figure 8: Experimental, numerical and $Z_{t r}$ law transition zone -Application I- 

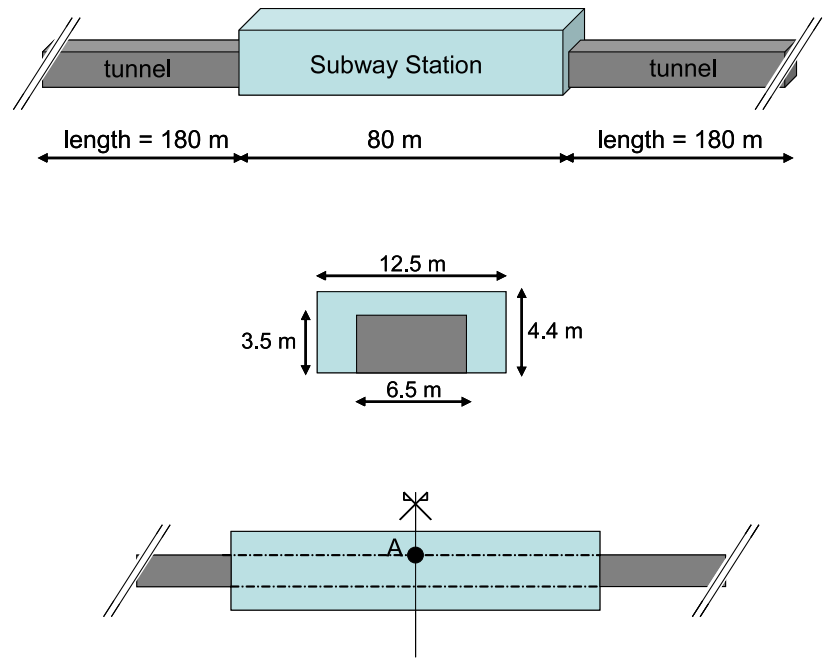

Figure 9: Subway station and explosive configuration -station and tunnel- Application II- 


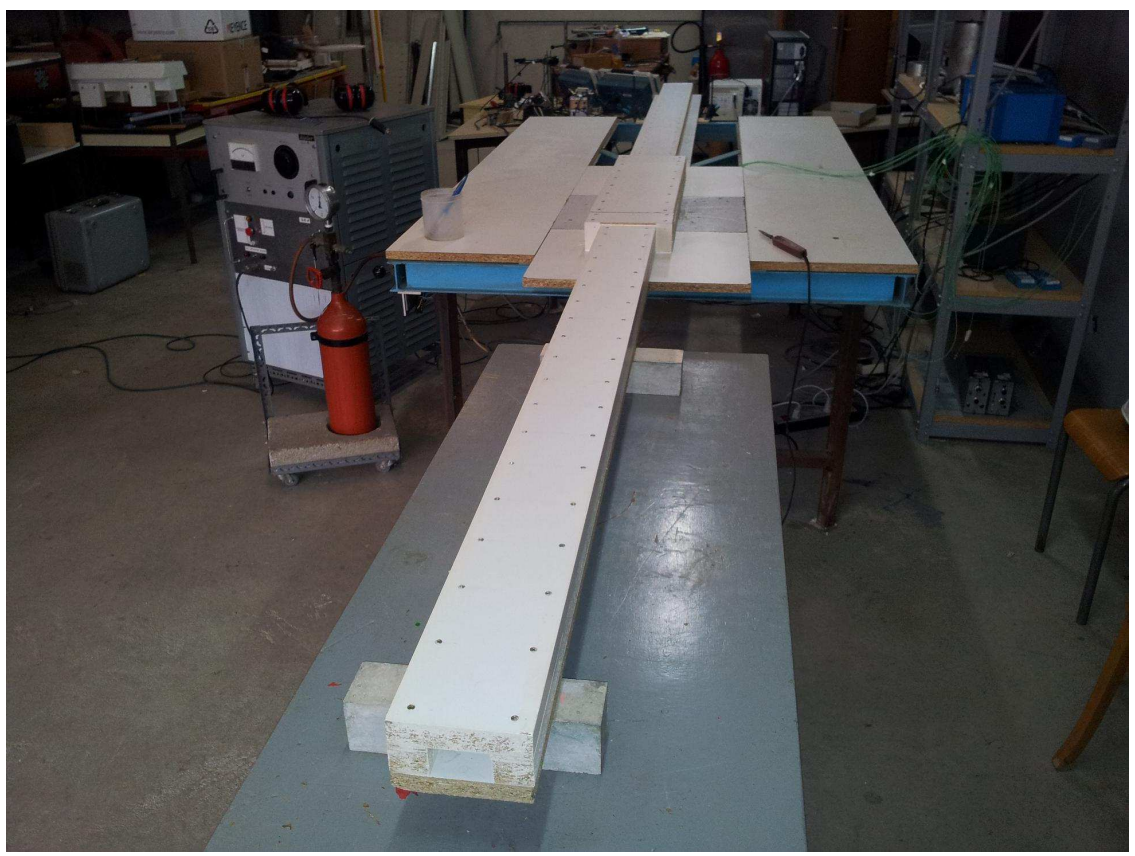

Figure 10: Subway station model -Application II- 


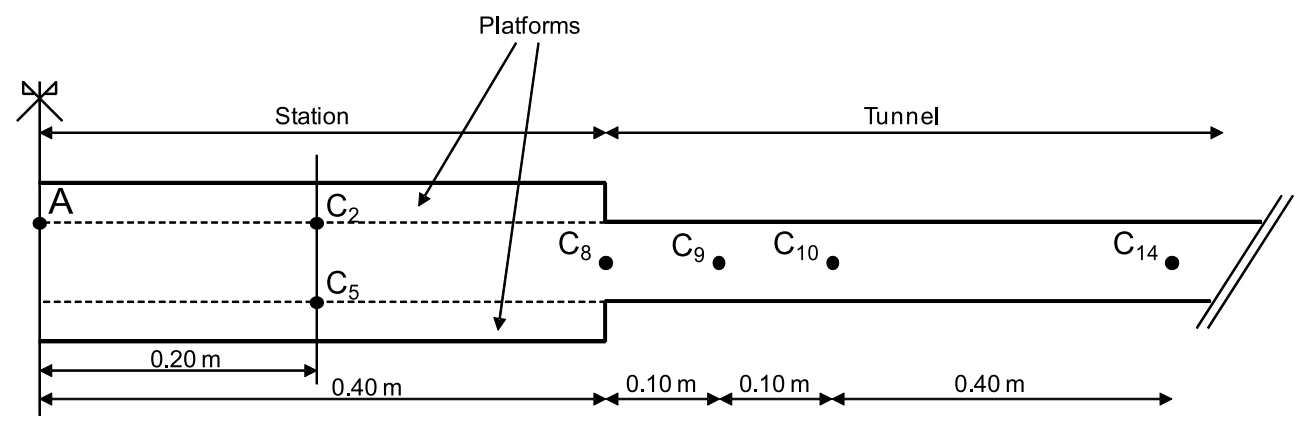

Figure 11: Position of the pressure sensors -Application II- 


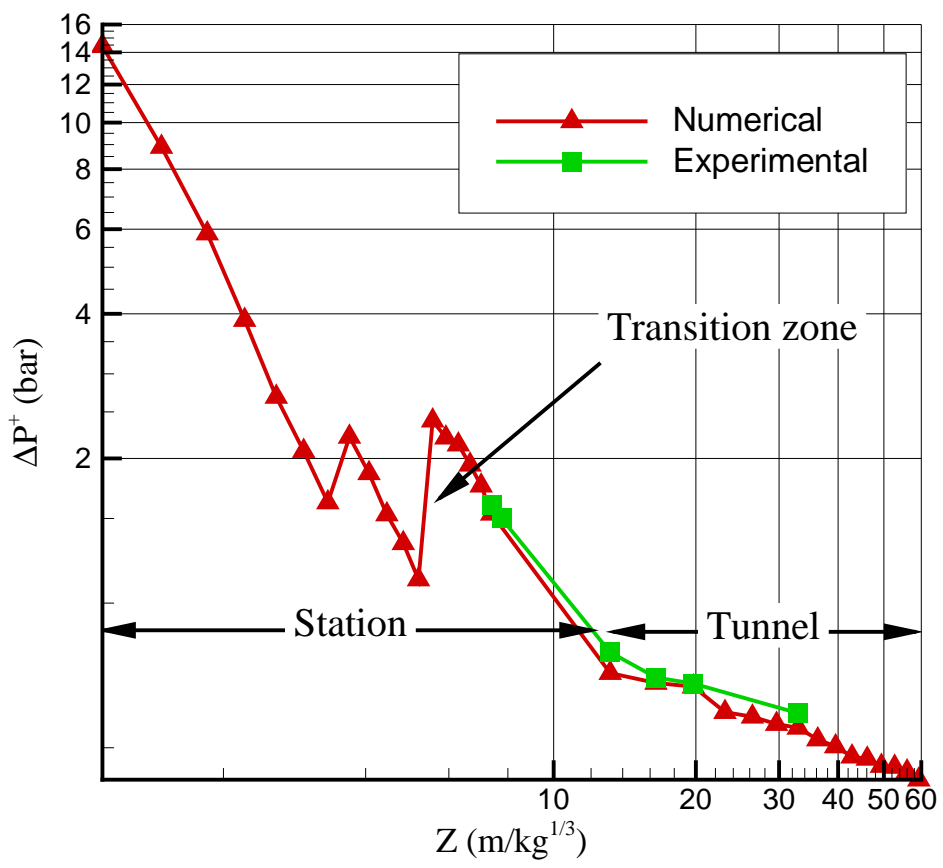

Figure 12: Overpressures in the station and in the tunnel -Application II- 
case (a): $t=4 \mu \mathrm{s}$

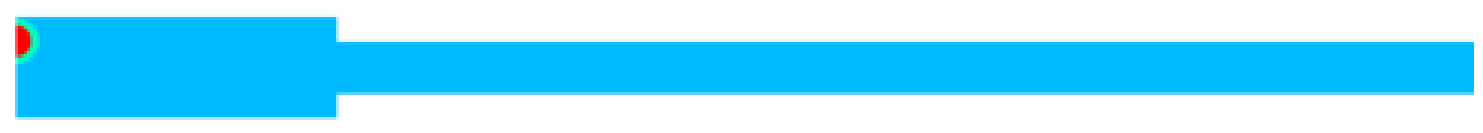

case (b): $t=1 \mathrm{~ms}$

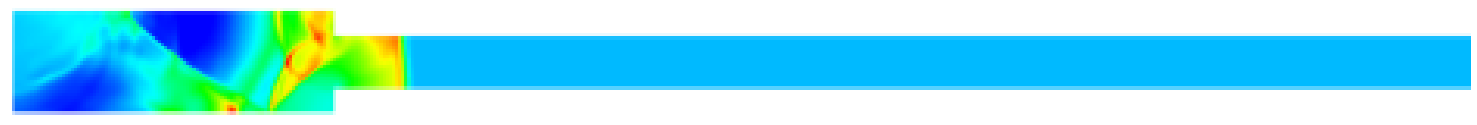

case $(\mathrm{c}): t=2 \mathrm{~ms}$

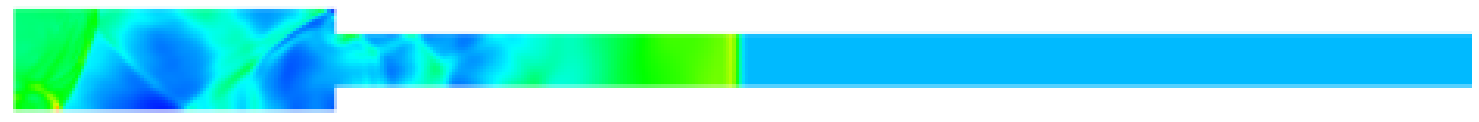

case $(\mathrm{d}): t=3 \mathrm{~ms}$

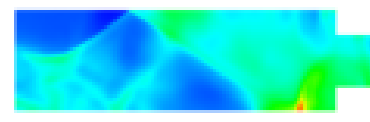

Figure 13: iso Mach at different times $(t=4 \mu \mathrm{s}, 1 \mathrm{~ms}, 2 \mathrm{~ms}$ and $3 \mathrm{~ms})$, top view -Application II- 


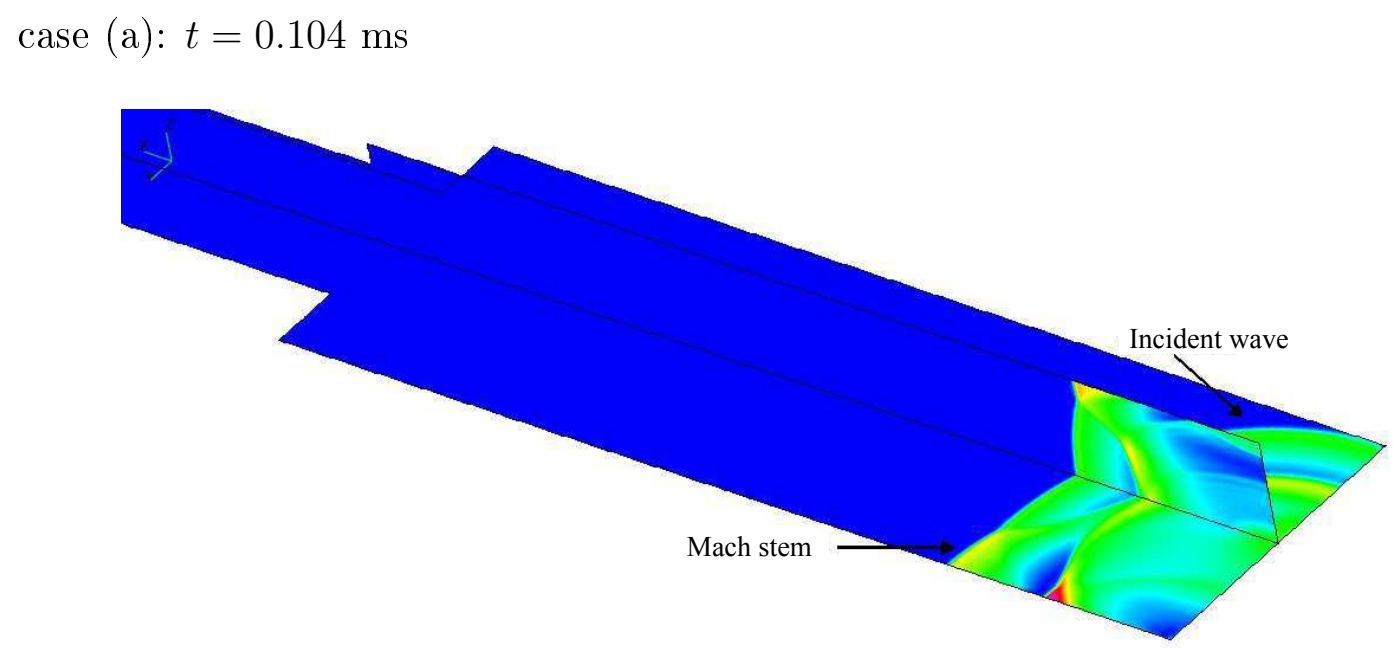

case (b): $t=0.204 \mathrm{~ms}$

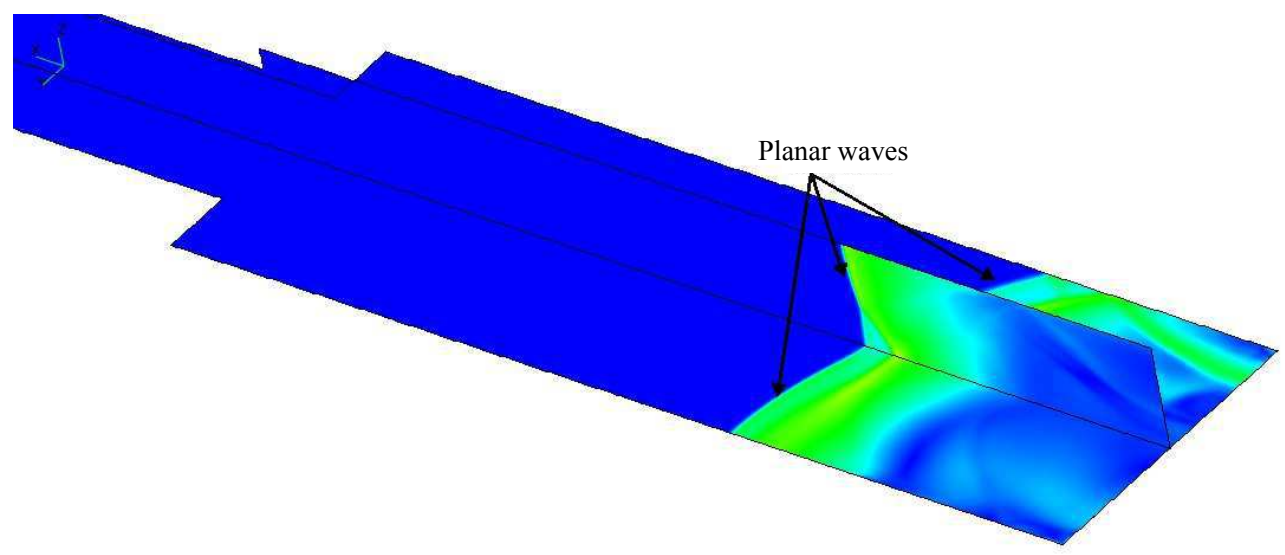

Figure 14: 3D iso Mach at different times in the station -Application II- 


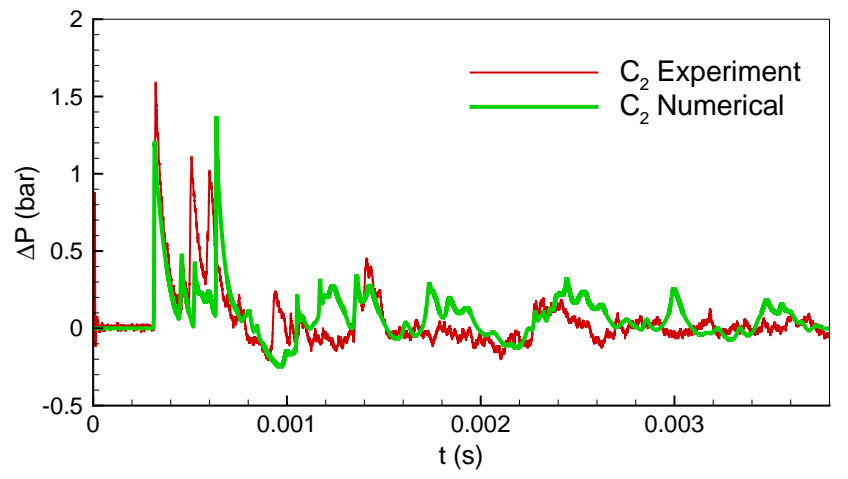

(a) Sensor $\mathrm{C}_{2}$

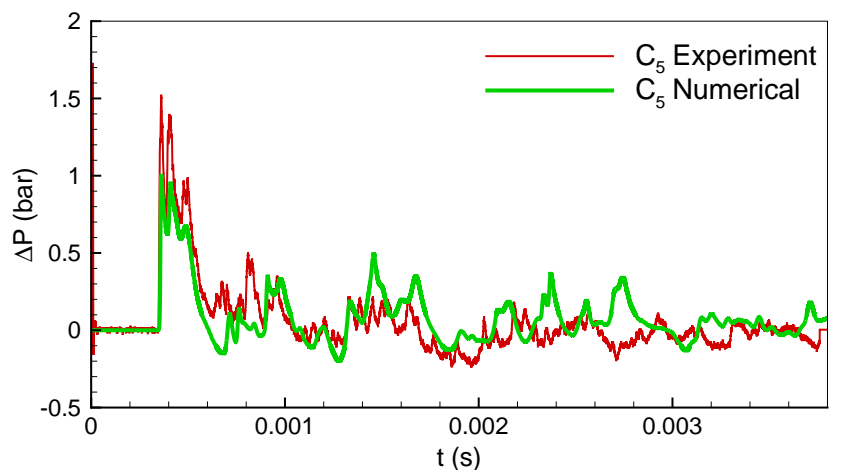

(b) Sensor $\mathrm{C}_{5}$

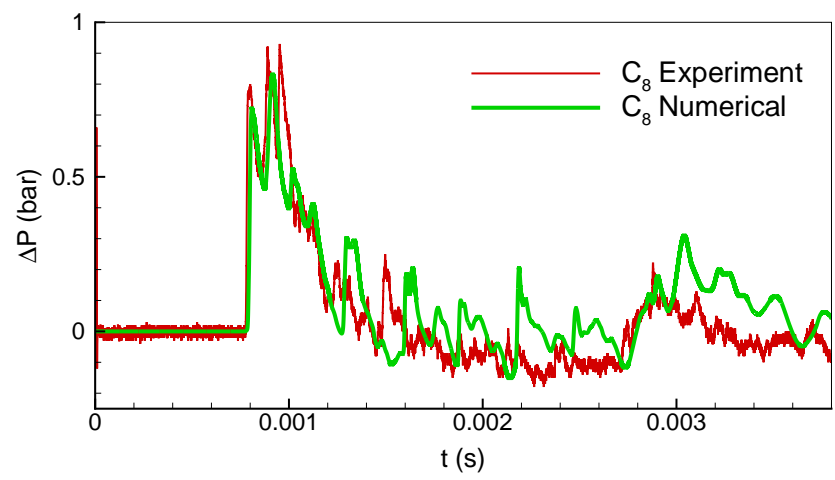

(c) Sensor $\mathrm{C}_{8}$

Figure 15: Incident pressures in the station: $\mathrm{C}_{2}, \mathrm{C}_{5}$ and $\mathrm{C}_{8}$-Application II- 


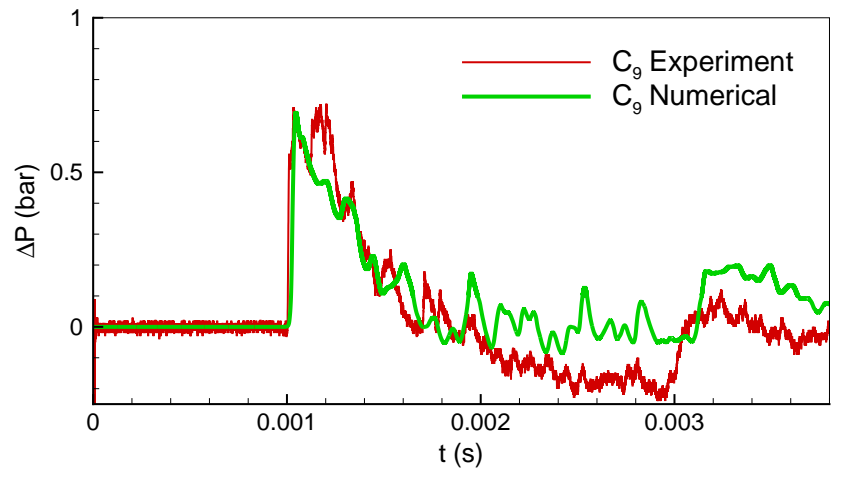

(a) Sensor $\mathrm{C}_{9}$

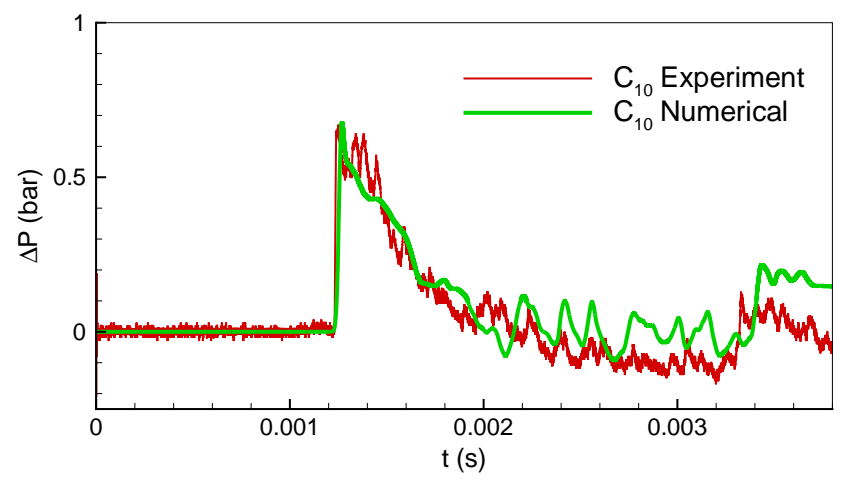

(b) Sensor $\mathrm{C}_{10}$

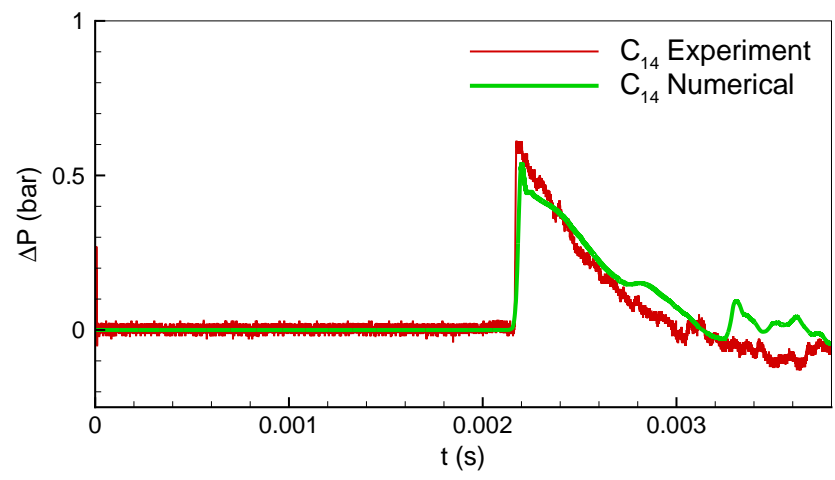

(c) Sensor $\mathrm{C}_{14}$

Figure 16: Incident pressures in the tunnel: $\mathrm{C}_{9}, \mathrm{C}_{10}$ and $\mathrm{C}_{14}$-Application II- 


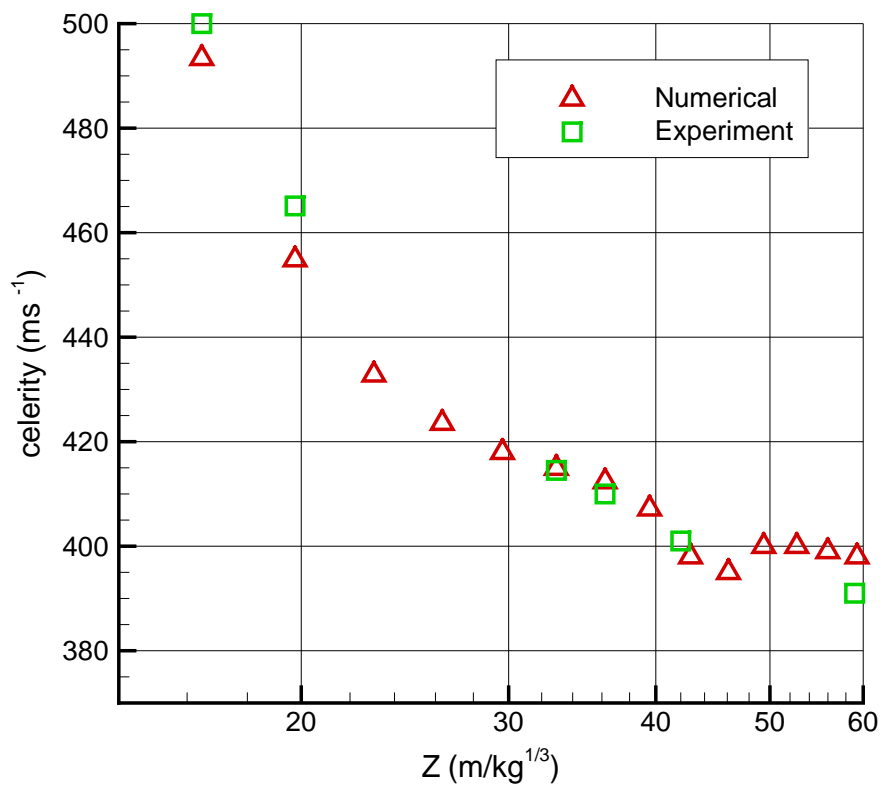

Figure 17: Celerity of the blast wave in the tunnel -Application II- 